\title{
Reseña de Sol Mora, Pablo, Miseria y dignidad del hombre en los Siglos de Oro, México, Fondo de Cultura Económica, 2017, 255 pp. ISBN: 9786071652614
}

\section{Carlos Tomás Elías}

Universidad Nacional de Salta

ARGENTINA

ct.elias.1h@gmail.com

[Hipogrifo, (issn: 2328-1308), 7.2, 2019, pp. 923-925]

Recibido: 24-06-2019 / Aceptado: 02-07-2019

DOI: http://dx.doi.org/10.13035/H.2019.07.02.66

Cuando Pablo Sol Mora, profesor de literatura y crítico literario mexicano, escribe Miseria y dignidad del hombre en los Siglos de Oro, da lugar a una obra que rastrea las concepciones antropológicas de los Siglos de Oro y sus antecedentes de la mano de las categorías miseria y dignitas. El autor da cuenta de una investigación en la que se muestran modos dicotómicos de concebir al hombre en los siglos de mayor esplendor de la literatura española. Sin embargo, para lograr esto, primero se sirve de un trabajo de reconstrucción de la historia intelectual en torno a las concepciones optimistas y pesimistas sobre el ser humano que se tuvieron desde el siglo $v$ a.C. hasta el siglo XV. Luego, examina el pensamiento de tres autores estelares del Renacimiento y tres del Barroco. De esta manera, la obra se divide en dos partes: la primera dedicada a la reconstrucción de la historia intelectual y la segunda, orientada al estudio de algunos de los exponentes más destacables del Renacimiento y del Barroco.

En la primera sección del libro se detallan las consideraciones antropológicas que se tuvieron en Occidente desde la Antigüedad hasta el Renacimiento. Se analizan las miradas de griegos y latinos en torno al hombre, cómo la patrística sintetizó el pensamiento de los clásicos con el pensamiento bíblico, las reformulaciones que se hicieron en el Medievo y los cambios que sucedieron en el Renacimiento. El autor recoge algunas de las reflexiones más importantes de cada época y explica cómo la miseria y la dignitas las teñían. Se muestra de qué manera en distintos períodos se veían en el ser humano características que lo dignificaban, pero también particularidades que permitían considerarlo como miserable. No obstante, se explicita 
de manera constante que nunca hubo una época en la que solo se viera en el hombre miseria o dignitas, aunque siempre estuvo presente la primacía de uno de estos elementos.

Una vez finalizado el estudio histórico de las ideas de la primera mitad del libro, se procede al inicio de la segunda parte que empieza con el análisis de cuatro obras insignes del Renacimiento, para luego continuar con el examen de tres obras distinguidas del Barroco con el fin de evidenciar con mayor claridad los cambios producidos de una época a otra. De esta manera, en una primera instancia el autor estudia la producción de tres famosos literatos de una época en la que por regla general se celebraban la excelencia del ser humano y sus capacidades, para luego hacer lo mismo con tres autores de un momento histórico en que las guerras y los conflictos usualmente tornaban a las reflexiones pesimistas y oscuras. Así, del Renacimiento se toman el Diálogo de la dignidad del hombre de Fernández Pérez de Oliva y su continuación hecha por Francisco Cervantes de Salazar, junto a De los nombres de Cristo de Fray Luis de León. Mientras que del Barroco se toman La cuna y la sepultura y La providencia de Dios de Francisco de Quevedo, La vida es sueño de Pedro Calderón de la Barca, y El Criticón de Baltasar Gracián.

La primera etapa de la segunda mitad del estudio, centrada en el Renacimiento, inicia con el análisis del Diálogo de la dignidad del hombre de Fernández Pérez de Oliva debido a que se considera que este es el primer texto escrito en lengua vulgar que sintetiza, de manera lacónica y precisa, las discusiones renacentistas entre paganos que exaltan la miseria hominis y cristianos que favorecen la dignitas hominis, pero siempre haciendo especial énfasis en la preeminencia de este último elemento. Luego se examina la continuación y reelaboración de este diálogo que escribe Francisco Cervantes de Salazar donde, en un ejercicio retórico en el que extiende el texto original, incorpora argumentos propios del cristianismo para sostener la postura a favor de la miseria hominis, aunque sin quitar méritos a la postura que defiende la dignitas. Finalmente, cuando se toma De los nombres de Cristo de Fray Luis de León, se elige tratar una obra producida en un momento histórico en el que las persecuciones eran normales ante cualquier posible sospecha de traición o herejía. En esta obra, mientras se busca poner al mensaje bíblico al alcance de todos y evitar sus malas lecturas, se explica cómo el hombre, hecho en principio a imagen y semejanza de Dios, pierde parte de su dignidad al caer en el pecado y luego la recupera por gracia de Cristo. En el estudio de esta última obra de finales del Renacimiento se exalta la dignitas hominis por mérito del sacrificio del hijo de Dios que permite a los seres humanos recuperar su dignidad.

La segunda etapa de la segunda mitad del estudio, centrada en el Barroco, empieza con La cuna y la sepultura y La providencia de Dios de Francisco de Quevedo, se escogen obras propias de un momento de crisis económico-sociales en España donde se agudiza la mirada sobre la miseria hominis. Allí el pesimismo sobre la condición humana es claro y se atribuye al desconocimiento que tiene el ser humano sobre sí mismo, a la vanidad y a la soberbia. Cuando se toma La vida es sueño de Pedro Calderón de la Barca, se aborda el estudio de lo que se considera como la mejor expresión dramática de la miseria y la dignitas hominis de los Siglos de 
Oro en tanto la reflexión sobre la condición humana es central para el desarrollo del texto. La obra analiza cómo la humanitas no es algo con lo que se nace, sino algo que se consigue solo a partir del voluntario uso del entendimiento que no siempre es empleado. Finalmente, cuando se elige tratar El Criticón de Baltasar Gracián, se toma una obra que se sirve de argumentos mayormente secular para explicar las distintas formas de degeneración humana en un mundo en el que imperan el engaño y la apariencia, un mundo en el que solo a través de la educación el hombre puede ser persona.

Con los autores y las obras que Sol Mora elige tanto del Renacimiento como del Barroco, muestra la preocupación propia de los Siglos de Oro sobre cuál es la condición del hombre y exhibe el uso que se les da en la literatura a los argumentos esgrimidos por paganos y cristianos. Además, da cuenta de la estructuración tomada por los argumentos optimistas y pesimistas que hay en relación a la condición humana. La selección realizada cumple con el propósito de presentar casos paradigmáticos del humanismo correspondiente a una España matizada en su historia por su "imperialismo" con Carlos $V$, su enrarecimiento en el reinado de Felipe Il por el sombrío ambiente religioso y en general por las abundantes crisis propias del siglo XVI. De esta manera, se presenta la producción generada en momentos históricos disímiles y los matices que ello implica al momento de considerar cómo es el hombre y cuáles son sus características principales.

Miseria y dignidad del hombre en los Siglos de Oro de Sol Mora es un libro que permite acceder a una comprensión de las reflexiones antropológicas presentes en la literatura en distintos momentos de la historia y sus relaciones con los sucesos histórico-sociales que las condicionaron. Sin embargo, el autor deja en claro que lo histórico-social no es determinante para la producción, en toda época hay concepciones sobre el ser humano que, aunque puedan ser aparentemente similares en muchos puntos, son diferentes. 